August 6, Sunday.-I was at the English church this morning. It is a nice little church, and there was a congregation composed of the Hudson's Bay people, twenty or thirty. Most of the Hudson's Bay people are Scotch, many coming from the Orkneys. The Bishop Bompas is very pleasant, he is a great traveller, and has lived amongst the Esquimaux at the mouth of the Mackenzie River, and he works very hard.

August 9.- The weather has been stifling hot, $89^{\circ}$ indoors, for the last three days, quite like the West Indies. Yesterday I went over to see a performance at the Roman Catholic Mission of the school children, got up by the sisters in our honour. They sang, and acted, and danced remarkably well. They have very good memories I am told.

It is curious living together without money, as one does in this country. Everything is done by barter, the unit of value being a skin; the average value of a beaver skin is said to be worth twenty ducks, or forty white fish, or twenty plugs of tobacco, so that for a plug of tobacco (about an $\frac{1}{2} \mathrm{oz}$.) one can get a duck or two white fish, a large fish about two feet long, and very good eating. This place, like all other habitations in the north-west, swarms with large wolf-like dogs. These are used in winter for drawing carrioles, and a team of four dogs will draw 500 lbs. or more. The Indians use them too, in summer, as pack animals.

The boats have just made their appearance, four black specks on the horizon to the north, so we shall be off in a few hours.

\section{THE SWEDISH EXPEDITION TO SPITZBERGEN, 1882}

THE results of the researches of the expedition de1 spatched to Spitzbergen last summer by the Swedish Academy of Sciences, under the eminent savants Baron G. de Geer and Dr. Nathorst, for the study of the geological and geographical features of the island, are very interesting. In the first instance, these gentlemen have drawn two maps, showing the exact geographical features of the island, as compared with those prepared by two previous expeditions. Of these, one shows the outlines of the fjords and valleys in the southern part of the island, with the boundary of the inland ice, and the other the relative depth of the seas around Spitzbergen and Scandinavia. From the latter it appears, that these two land-formations are really elevated ridges on a comparatively level plateau, which sinks abruptly in the ocean west of Spitzbergen. In the second instance, the expedition has ascertained that the deep fjords and narrow valleys of the island have not been formed by upheaval of the terrestrial crust or by strong water-courses, but are due to the action of glaciers during the Glacial period, while from the marks on the rocks of the Beeren Island, it may be assumed that the Spitzbergen glaciers extended even so far.

At the close of the Glacial period a sudden subsidence, followed by a still greater rising of the shores, both of Spitzbergen and Scandinavia, most probably took place, which is demonstrated by the discovery, in Scandinavia as well as Spitzbergen of old gravel beaches and the shells of salt-water mussels far inland. The existence in Spitzbergen of some of the most characteristic species of the Scandinavian flora and fauna, may perhaps be explicable by migration from Scandinavia, at a period when the plateau between the two ridges was above the level of the sea, we may assume, shortly after the close of the Glacial period. It seems impossible to explain otherwise how, for instance, birds, particularly those living on land, could have found their way to this island, some 700 miles distant from the Scandinavian peninsula.

At the same period, the common Scandinavian "Blaamusling," Mytilus edulis, and a few other species have, no doubt, also migrated into the island. This species is now, however, extinct, but the large quantities of shells found on the shores indicate that at one time it must have been common enough. The latter circumstance seems to prove that the climate of Spitzbergen at an earlier period was much milder than at present, and corroborates also the theory of a connection having existed between Spitzbergen and Scandinavia about the Glacial period, as such a land-barrier would have caused the eastern arm of the Gulf Stream, which now flows by the North Cape. to have taken a more northerly direction, and thus carried the softening elements of a southern clime to the now desolate rocks in the Arctic Ocean.

\section{THE INCREASE IN THE VELOCITY OF THE WIND WITH THE ALTITUDE}

$T \mathrm{HE}$ fact that the upper strata of the atmosphere as a rule move more rapidly than those near the earth's surface, has long been inferred on theoretical grounds, though little direct evidence beyond the marvellous and often unexpected voyages of aëronauts, or casual observation of the clouds, has hitherto been furnished in its favour. The prectical value of this fact is beginning to be felt by engineers since the investigations undertaken by Mr. T. Stevenson in 1876, and more recently (see Journal of Scottish Meteorological Society, vol. v. pp. IO3 and 348), showed that even for moderate heights the old notion of assuming the wind to be of uniform velocity at all altitudes was seriously in error, and that to rely upon it in the case of lofty structures might entail disastrous consequences.

While Mr. Stevenson's experiments have shown that the wind's velocity increases very considerably, especially near the surface, they do not touch the question of the increase noticed at great heights, nor can the formulæ or conclusions derived from them be said to throw any light on a matter which evidently contains the germs of many important truths for the meteorologist.

Where the engineer ends in fact the meteorologist may be said to begin; but in this case the engineer ends a little too soon, since Mr. Stevenson's latest experiments terminate at the top of a pole only 50 feet high, where he leaves us with a formula "believed to be sufficiently accurate for practical purposes," and which is said to give the velocity for "great heights" above sea-level." Whence Mr. Stevenson obtains this formula, or on what data he believes it to be approximately correct, we are not told, and here the question is left in a state of uncertainty for greater heights, in which we trust neither engineers nor meteorologists will allow it long to remain. It might even be advantageous to the former, if instead of trusting to a few empirical formula, they would ask the meteorologists what they knew about the matter, and joined with them in endeavouring to discover a rational formula which would yield satisfactory results at all elevations.

Theoretically the main factor at small elevations in determining the increase of velocity, would appear to be the diminution of friction as we rise above the surface, and as this must occur most decidedly near the surface, so the velocity must increase in the first few feet "per saltum." Mr. Stevenson's experiments and curves show this very clearly. Indeed up to a height of 15 feet the increase is so sudden, so irregular, and so clearly dependent on the nature of the surface, that no attempt has been made to include this space within a formula.

There is, however, another factor which acts positively in the same direction, and which, while operating for the most part at great heights, where its influence ultimately predominates to the exclusion of the friction factor, must be felt to some extent at comparatively moderate elevations.

I allude to the general increase in the barometric 
gradient with the height above the earth's surface, due to the general temperature gradient between the equator and the poles, in conjunction with the earth's rotation. This fact has been thoroughly investigated by Mr. Ferrel of the U.S. Coast Survey, and the results given in his "Meteorological Researches," vol. i. In this work he has given on p. 45 the mean west-easterly component of the velocity at the surface due to the causes just mentioned, and the term by which this increases with the height (in metres) for every fifth degree of latitude on the mean of all longitudes, for the months of January and July, and for mean annual temperatures, calculated from the observed barometric pressures and temperatures in every part of the world.

For latitude $50^{\circ}$ the eastward velocities at the surface and increment terms for the elevation are as follows in two different measures.

$$
\text { Mean temperatures. }
$$$$
\text { January. }
$$$$
\text { July. }
$$

Miles per hour $3 \cdot 35+8 \cdot 6 h \quad \ldots \quad 3 \cdot 97+12 \cdot 1 h \quad \ldots 2 \cdot 73+5 \cdot 1 h$

Feet per second $4^{\circ} 91+{ }^{\circ} 0024 h \ldots 5^{\cdot} 82+{ }^{\circ} \mathrm{OO} 33 h \ldots 4^{\circ} \mathrm{OO}+{ }^{\circ} \mathrm{OO} 14 h$ where $h$ represents the height in miles and feet respectively. ${ }^{1}$

Owing to this cause alone therefore the eastward (and therefore in our latitudes the prevailing) motion of the atmosphere will be increased on the mean of the year by $8 \frac{1}{2}$ miles per hour at a height of 528 o feet, or by $2 \frac{1}{8}$ miles per hour at a height of about I 300 feet.

The increase in the horizontal velocity which results from the joint action of these two factors, is thus probably very different from that which would arise from a mere diminution of friction alone, since at great heights this would theoretically become almost insensible.

For a thoroughly satisfactory solution of the matter, nothing will avail except anemometrical observations made at every possible elevation (preferably, as I lately suggested in a paper read before the Meteorological Society, with instruments attached to kite-strings), but in the absence of these at present, it may be worth while to use some excellent observations on the velocity of different cloud-layers recently communicated to the Austrian Zeitschrift für Meteorologie, by Dr. Vettin, ${ }^{2}$ for the purpose of showing the complete breakdown of Mr. Stevenson's formula when applied to "great heights above sealevel."

The following table, which is taken from Dr. Vettin's paper, gives the mean velocity of the clouds from all directions, at five altitudes to which they respectively belong, and which, together with their velocities, have been measured by methods described in detail in the paper from which it is extracted :-

TABLE I.

$$
\begin{array}{ccccc}
\begin{array}{l}
\text { Name of } \\
\text { station. }
\end{array} & \begin{array}{c}
\text { Barometric } \\
\text { pressure. }
\end{array} & \begin{array}{c}
\text { Height } \\
\text { in } \\
\text { feet. }
\end{array} & \begin{array}{c}
\text { Number } \\
\text { of } \\
\text { observations. }
\end{array} & \begin{array}{c}
\text { Mean velocity } \\
\text { in feet per } \\
\text { second. }
\end{array}
\end{array}
$$

$\begin{array}{lllllllll}\text { Upper cirrus } & \ldots & \text { II ' } 968 & \ldots & 23,000 & \ldots & 879 & \ldots & 59.5\end{array}$

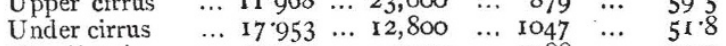

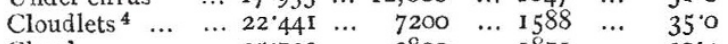

$\begin{array}{lllllllllll}\text { Cloud } & \ldots & \ldots & 25733 & \ldots & 3500 & \ldots & \text { I } 871 & \ldots & 30^{\circ} 4\end{array}$

$\begin{array}{llllllllll}\text { Under cloud } & \ldots & 28.127 & \ldots & 1600 & \ldots & 1292 & \ldots & 37^{\circ} 4\end{array}$

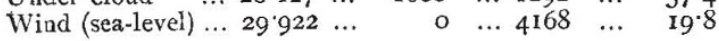

It will be seen from this table that while there is a rapid increase in the velocity of the wind through the first I600 feet, an abrupt diminution occurs between this height and 3800 feet, after which the motion again increases at a more moderate rate.

Now Mr. Stevenson's formula for heights above 50 feet is $\frac{V}{v}=\frac{H}{h}$, where $V, v, H, h$, are the velocities and heights

It must be noted that the surface velocities given in this table are some${ }^{x}$ It must be noted that the surface velocities given in this table are somewhat in excess of the truth, owing to the neglect of sur

does not affect the increment terms to any large extent. “ 2 Zeitschrift für Meteorologie, ,

3 Reduced from the original figures in millimetres. 4 Wölkchen. at the upper and lower stations respectively. If we apply this formula to the preceding table and calculate the heights at the higher levels from those at the lower ones, we get for the most favourable cases the following values :-

$$
\begin{array}{ccrrrrrr}
\multicolumn{3}{c}{\text { Observed }} & & & \multicolumn{3}{c}{\text { Calculated }} \\
\text { Velocity. } & & \text { Height. } & & & \text { Velocity. } & & \text { Height. } \\
37 \cdot 4 & \ldots & \text { I,600 } & \ldots & \ldots & \mathbf{2 5 9} \cdot \mathbf{2} & \ldots & \mathbf{1 2 , 8 0 0} \\
5^{1} \cdot 8 & \ldots & \mathbf{1 2}, 800 & \ldots & \ldots & \mathbf{1 1 3} 3^{\cdot 1} & \ldots & \mathbf{2 3}, 000
\end{array}
$$

which are so absurdly in excess of those observed at the same levels, and so far beyond what we might reasonably expect as to render it doubtful whether this formula is true for any height above the first 100 feet. Even the formula which is supposed by Mr. Stevenson to fail above 50 feet gives better results than this one at the higher levels.

$$
\text { This formula is } \frac{V}{v}=\sqrt{\frac{\overline{H+72}}{h+72}} \text {, and from the same }
$$

observed values as those used above gives the following calculated values :-

$$
\begin{array}{ccccccc}
\text { Height. } & & & & & & \text { Velocity. } \\
\text { I2,800 } & \ldots & \ldots & \ldots & \ldots & \ldots & 103.7 \\
23,000 & \ldots & \ldots & \ldots & \ldots & \ldots & 69.3
\end{array}
$$

but even these are far in excess of those observed. Both formulæ moreover fail lamentably up to 1600 feet, for even if we assume that 19.8 represents the velocity, not at sea-level, but at an elevation of roo feet above it (an exceedingly favourable assumption since the velocity at this height would considerably exceed that at sea-level), the first formula would make the velocity at I600 feet four times, and the second more than three times that actually observed by Dr. Vettin.

It is plain, therefore, that both formulæ must fail considerably below 1600 feet, and until further evidence is furnished it would seem probable that neither of them give correct results much above 100 feet or so.

For practical engineering purposes no doubt they would succeed only too well, since they would probably give a maximum velocity far in excess of the truth, and this, judging from examples such as the Tay Bridge, would be no disadvantage when the force of the wind enters into engineering calculations.

It would surely be better, however, if we could arrive at a somewhat closer approximation to the truth, and better still if we could arrive at the truth itself. This, as I have already pointed out, will be only accomplished for the lower strata by further experiment in the same direction as that already followed by Mr. Stevenson, modified by attaching anemometers to kite strings, and for the upper strata, which chiefly concern the meteorologist by observations of the clouds similar to those made by Dr. Vettin.

Meanwhile, however, I have found a formula which gives very much more satisfactory values at the higher

\begin{tabular}{|c|c|c|c|c|c|c|}
\hline \multirow{3}{*}{$\begin{array}{c}\text { Height of lower } \\
\text { stratum. } \\
3,800 \\
\text { I, } 600\end{array}$} & \multicolumn{3}{|c|}{ TABLE II } & \\
\hline & & $\begin{array}{l}\text { Height of upper } \\
\text { stratum. }\end{array}$ & & Observed. & Telocit & Calculated. \\
\hline & $\cdots$ & 7,200 & $\ldots$ & 35 & $\ldots$ & $35^{\circ} 6$ \\
\hline $\left.\begin{array}{l}1,600 \\
7,200\end{array}\right\}$ & $\cdots$ & 12,800 & $\cdots$ & $5 \mathrm{I} \cdot 8$ & $\cdots$ & $5^{1} \cdot 5^{1}$ \\
\hline 12,800 & $\ldots$ & 23,000 & $\cdots$ & $59 \%$ & $\ldots$ & 59.5 \\
\hline 23,000 & $\ldots$ & 41,000 & $\ldots$ & $67^{2}$ & $\ldots$ & $68 \cdot 7$ \\
\hline
\end{tabular}
levels than those furnished by Mr. Stevenson. This formula is-

$$
\frac{V}{v}=\sqrt[4]{\frac{\bar{H}}{h}}
$$

And although I do not expect it will be found to hold very near the surface, it certainly accords, omitting the anomalous case at 3800 feet, from 1600 feet to 23,000 feet, or through a range of $2 \mathrm{I}, 4 \mathrm{CO}$ feet, very closely with the values observed by Vettin.

The figures observed and those calculated from this formula are as follows :- 
Moreover, if we assume that 19.8 is the velocity at 100 feet, the velocity at $I, 600$ feet calculated from it by this formula would be almost exactly equal to that observed, instead of four times as much as it was when calculated from $\frac{V}{v}=\frac{H}{h}$. The empirical formula $v=28 \cdot 1+0.2 \sqrt{h}$, where $z^{\prime}$ is the velocity in feet per second, and $h$ is the corresponding height in feet, gives for the four elevations above, results in close agreement with those observed, but it would probably fail below I, 600 feet.

Mr. Stevenson in his first paper uses a formula $\frac{F}{f}=\sqrt{\frac{\bar{H}}{h}}$ where $F f$ are the forces ("pressures" I suppose is meant by this objectionable word) at the two levels corresponding to $H$ and $h$.

In his second paper he says he prefers the formula $\frac{V}{v}=\frac{H}{h}=\frac{P}{p}$, where $P$ and $p$ are the pressures at the two levels to the formula $\frac{V}{v}=\frac{\sqrt{H}}{\sqrt{h}}$, from which and some other remarks it would appear that pressure and velocity are considered to vary directly with each other. This is a notion which is certainly at variance not only with the hitherto generally accepted empirical formulæ, but is distinctly contrary to the results lately deduced by $\mathrm{Mr}$. Ferrel from the hydrodynamical theory (see Van Nostrand's Engineering Magazine, vol. xxvii. p. I4I). The formula usually found in the text-books is $\not p=00492 v^{2}$, and the one deduced by Ferrel is

$$
p=\frac{.0027}{\mathrm{I}+.003665 t} \frac{P}{P^{\prime}} v^{2},
$$

where $P P$ are the barometric pressures at the level under consideration and at sea-level respectively, and $t$ is the temperature in degrees Centigrade ; and though from the latter formula it is evident that the pressure at the higher levels will be iess for the same velocity than below (at the height of Mont Blanc, for example, it would be reduced by about one-half) there is nothing to lead us to infer that $\frac{V}{v}=\frac{P}{p}$.

If in the formula $\frac{F}{f}=\sqrt{\frac{H}{h}}$ which was discarded by Mir. Stevenson, we make the ordinary assumption that $\frac{F}{f}=\frac{V^{2}}{v^{2}}$ we get the formula which I have already shown gives results which agree closely with the values observed by Vettin above I, 600 feet, and which even below this height is much nearer the truth so far as can be inferred from the slender data employed, than the formula preferred by Mr. Stevenson.

If we take the heights as abscissæ, the curve traced out by the velocity-ordinates will be much flatter than the ordinary conical parabola, and at great heights will approximate very nearly to a straight line parallel to the axis. Ferrel's increment-term makes it a straight line all through, but his formula assumes that the temperature gradient between the pole and the equator is the same above as at the earth's surface, it leaves out friction altogether, and also supposes the velocity for the same gradient to be the same at all heights, whereas according to theory it should increase with the height in the ratio $\frac{\cos i}{P}$, where $i$ is the angle the wind ma'res with the isobar, and $P$ is the barometric pressure at the level under consideration. Notwithstanding these omitted factors, of which the first and last probably tend to destroy each other, it will be found that the addition of the increment corresponding to each altitude to the velocity at the surface observed by Vettin gives us the following fair approximation to the values actually observed, though the calculated values are too small at 1600 feet and too large at 23,000 feet by just about the same amount :-

$$
\begin{aligned}
& \text { Height. } \quad \begin{array}{c}
\text { Velocity } \\
\text { observed. }
\end{array} \quad \begin{array}{c}
\text { Calculated from } \\
\text { Ferrel's Formula }
\end{array} \\
& \begin{array}{llllllllll}
23,000 & \ldots & \ldots & \ldots & 59^{\circ} 5 & \ldots & \ldots & \ldots & 75^{\circ}
\end{array}
\end{aligned}
$$

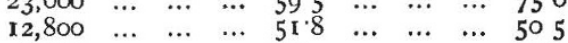

$$
\begin{aligned}
& \begin{array}{llllllllll}
7,200 & \ldots & \ldots & \ldots & 35 & \ldots & \ldots & \ldots & 37^{\circ} 0
\end{array} \\
& \begin{array}{lllllllll}
3800 & \ldots & \ldots & \ldots & 30.4 & \ldots & \ldots & \ldots & 28 \\
1
\end{array} \\
& \begin{array}{lllllllll}
1,603 & \ldots & \ldots & \ldots & 30 \cdot 4 & \ldots & \ldots & \ldots & 28 \\
0 & \ldots & \ldots & 374 & \ldots & \ldots & \ldots & 23 \cdot 6
\end{array} \\
& \begin{array}{lllll}
0 & \ldots & \ldots & \ldots & 19 \cdot 8
\end{array}
\end{aligned}
$$

In conclusion, it is evident that, quite apart from the meteorological side of the question, more investigation; like those undertaken by Mr. Stevenson, are urgently required to determine the actual rate of increase of the velocity at moderate heights, from which a formula like the one I have recommended may be deduced, which will yield values more within the range of probability than those furnished by the one which is apparently supposed to suffice for the rest of the atmosphere after we have reached the top of the fifty-foot pole.

\section{E. DOUGlas ARCHIBALD}

\section{KRAO, THE "HUMAN MONKEY"}

THROUGH the courtesy of Mr. Farini, I have had a private interview with this curious little waif, which he is now exhibiting at the Royal Aquariun, Westminster, and for which be claims the distinction of being the longsought-for " missing link" between man and the Anthropoid apes. Krao certainly presents so.ne abnormal peculiarities, but they are scarcely of a sufficiently pronounced type to justify the claim. She is, in fact, a distinctly human child, apparently about seven years old, endowed with an average share of intelligence, and possessing the faculty of articulate speech. Since her arrival about ten weeks ago in London, she has acquired several English words, which she uses intelligently, and not merely parrot-fashion, as has been stated. Thus, on my suddenly producing my watch at the interview, she was attracted by the glitter, and cried out $c^{\prime} o c k, c^{\prime} o c k$, that is, clock, clock! This showed considerable powers of generalisation, accompanied by a somewhat defective articulation, and it appears that her phonetic system does not yet embrace the liquids $l$ and $r$. But in this and other respects her education is progressing favourably, and she has already so far adapted herself to civilised ways, that the mere threat to be sent back to her own people is always sufficient to suppress any symptoms of unruly conduct.

Physically Krao presents several peculiar features. The head and low forehead are covered down to the bushy eyebrows with the deep black, lank, and lustreless hair, characteristic of the Mongoloid races. The whole body is also overgrown with a far less dense coating of soft, black hair about a quarter of an inch long, but nowhere close enough to conceal the colour of the skin. which may be described as of a dark olive-brown shade. The nose is extremely short and low, with excessively broad nostrils, merging in the full, pouched cheeks, into which she appears to have the habit of stuffing her fo od, monkey-fashion. Like those of the anthropoids her feet are also prehensile, and the hands so flexible that they bend quite back over the wrists. The thumb also doubles completely back, and of the four fingers, all the top joints bend at pleasure independently inwards. Prognathism seems to be very slightly developed, and the beautiful round black eyes are very large and perfectly horizontal. Hence the expression is on the whole far fro n unpleasing, and not nearly so ape-like as that of many Negritos, and especiaily of the Javanese "Ardi," figured by me in NATURE, vol. xxiii. $\mathrm{p} 200$. But it should be mentioned that when in a pet, Krao's lips are said to protrude so far as to give her "quite a chimpanzee look."

Apart from her history one might feel disposed to 